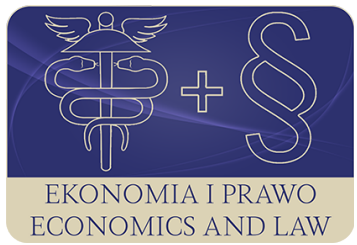

EKONOMIA I PRAWO. ECONOMICS AND LAW

Volume 19, Issue 1, March 2020

p-ISSN 1898-2255, e-ISSN 2392-1625

www.economicsandlaw.pl

ORIGINAL ARTICLE

received 30.03.2019; revised 07.12.2019; accepted 31.03.2020

Citation: Baran, B. (2020). Plastic waste as a challenge for sustainable development and circularity in the European Union. Ekonomia i Prawo. Economics and Law, 19(1): 7-20. doi:10.12775/EiP.2020.001.

\title{
Plastic waste as a challenge for sustainable development and circularity in the European Union
}

\author{
BERNADETA BARAN \\ Wroclaw University of Economics and Business, Faculty of Economic Sciences, Department \\ of Economic Policy and European Regional Studies, \\ ul. Komandorska 118/120, 53-345 Wrocław, Poland \\ ๑ bernadeta.baran@ue.wroc.pl \\ (D) orcid.org/0000-0003-1526-2954
}

\begin{abstract}
Motivation: Plastics are valuable materials covering a wide range of applications in everyday life and have the potential to be recycled many times while retaining their value and functional properties. However, the scale of the problem associated with improper management of plastic waste in the EU is enormous, which entails economic costs (the potential associated with the recycling of plastic waste remains largely unexploited) and irreversible losses for the environment. Solving the problems of plastic waste becomes the strategic goal of the EU, which takes action to support transition towards a circular economy and adopts first-ever Europe-wide strategy on plastics. These issues are current and important.
\end{abstract}

Aim: The aim of the article is to assess the previous efficiency of plastic waste management in the EU countries which, so far, results from the implementation of national policies. The Strategy for Plastic waste will be also discussed as a response to contemporary challenges and as an element of achieving the goals of sustainable development and circular economy.

Results: In the last years, the efficiency of plastic waste management have improved but still a huge share of plastic is wasted. The challenge is to increase recycling rates and to change unfavorable structure of plastic waste reuse: at this time energy recovery rate $(41.6 \%)$ is still higher than the recycling rate (31.1\%), and the recycling rate only slightly exceeds the landfill rate (27.3\%). The second problem concerns single-use plastic packaging which accounts for about $60.0 \%$ of the plastic waste in the EU. Adopting first 
ever European plastics strategy, the EU addresses environmental problems and solutions to help the transition to a CE. The goals are ambitious but realistic to meet in the coming years. They can bring a real change but at the same time this is just the beginning of the process.

Keywords: plastics; circular economy; sustainable development JEL: Q53; Q57; Q5

\section{Introduction}

The first synthetic polymer was invented in 1869. Thirty eight years later an industrial method of production was developed making it possible to manufacture plastics on a large scale. World War II created 'favourable circumstances' for the development of the industry, e.g. parachutes were produced from the world's first fully synthetic fibre-nylon and aircraft windows from plexi-glass (Science History Institute, 2018). In 1950, the world's production of plastics amounted to 1.5 billion tonnes. In the period 1950-2017 production increased by $8.6 \%$ per year, with the highest dynamics in the last decade of the 20th century. In 2017, global production amounted to 348 billion tonnes and is expected to double again over the next 20 years (PlasticsEurope, 2018).

Europe $^{1}$ is the second largest plastic producer (2017), with a $18.5 \%$ share of world production $(29.4 \%$ comes from China and $17.7 \%$ from NAFTA member countries). The six larger European countries cover almost $70.0 \%$ of the European demand: Germany (24.6\%), Italy (14.0\%), France (9.6\%), Spain (7.7\%), United Kingdom (7.3\%) and Poland (6.5\%). The European plastics industry includes plastics raw materials producers, plastics converters, plastics recyclers and plastics machinery manufacturers. The market sectors with the highest plastic converter demand are: packaging (39.7\%), building and construction (19.8\%), automotive (10.1\%), electrical and electronic (6.2\%), household, leisure and sports (4.1\%), agriculture (3.4\%) and others (Eurostat, 2018; PlasticsEurope, 2018).

The concept of plastics (polymers) is a very broad one. This name refers to materials whose basic components are polymers, i.e. multimolecular chemical compounds obtained in industrial polymerization processes (from so-called mers) and auxiliary components (additives). These additives make it possible to improve the mechanical and thermal properties of plastic products, increase their aesthetic value and at the same time reduce the price and give them special functional properties, e.g. non-flammability, resistance to light, low coefficient of friction, resistance to dirt (Ambrogi et al., 2017, pp. 87-108).

Plastics are valuable materials covering a wide range of applications in everyday life and have the potential to be recycled many times while retaining their value and functional properties. However, within the EU-28, a large share of this material is currently wasted. It means that on the economic side, the potential associated with the recycling of plastic waste remains largely unexploited.

\footnotetext{
${ }^{1}$ Europe includes the EU countries, Norway and Switzerland.
} 
On the other hand, there are serious environmental externalities related to plastic waste concentrating in three areas: degradation of natural systems as a result of leakage (especially in the oceans), greenhouse gas emissions resulting from production and after-use incineration, health and environmental impacts from microplastics and additives. Research estimates that from the 1950s, i.e. from the beginning of the plastics industry's development until $2015,70.0 \%$ of plastics waste has been accumulated in landfills or in the environment (Geyer et al., 2017). The scale of the problem associated with improper management of plastic waste is therefore enormous, which entails economic costs and, above all, irreversible losses for the environment. In response to these challenges, the EU countries take actions to increase the plastic reuse (as well as to reduce its use). This article assesses the effectiveness of these activities and reviews recent EU regulations aimed at accelerating the circular economy.

\section{Methods}

Statistical and deductive methods are used in this work. The considerations in this paper are based, to a great extent, on literature on the subject-matter and secondary data (a review of the literature assessing the effects of the plastic revolution on the environment and justifying the need for transition to a circular economy was carried out). The figures used for the analysis were mainly derived from Eurostat database, PlasticsEurope (associations representing plastics producers), The Ellen MacArthur Foundation (a charity working with business, government \& academia to build a framework for a circular economy) and environmental organizations. The main indicators analyzed in this paper are Recovery and landfill rate of plastic waste and Recycling rate of packaging plastic waste. To show the scale of the problem, the sizes of plastic waste and single-use plastic packaging in the EU were also indicated. Statistical analysis is preceded by the interpretation of regulatory solutions in the EU - Circular Economy Package and its main part - European Strategy for Plastic.

\section{Literature review}

Scientists became interested in the effects of the plastic revolution when the Great Pacific garbage patch was observed at the end of the 20th century (National Ocean Service, 2019). Particular attention was paid to the growing pollution of the marine environment, where $80.0 \%$ of waste are plastics, mainly single-use one. It has been estimated that more than 150 million tonnes of plastic waste have been accumulated in world oceans since 1980, of which between 1.4 and 3.7 million tonnes in EU seas. The world oceans receive between 8 and 13 million tonnes of plastic waste per year, i.e. between 1.5 and $4.0 \%$ of plastics world production (Jambeck et al., 2015). In the EU, between 150,000 and 500,000 tonnes of plastic waste end up in the seas each year, including particularly sensitive areas such as the Mediterranean Sea and some parts 
of the Arctic Ocean. This phenomenon leads to irreversible environmental changes. Fragments into which plastics is broken down, both larger and smaller (so-called microplastics), are found in all parts of the oceans. They have a significant impact on the whole ecosystem - entering the food chain, they get back to the human being, affecting his health (Watkins \& Brink, 2017).

Other negative effects are greenhouse gas emissions resulting from production and after-use incineration. Global plastic production and the incineration of plastic waste generate approximately 400 million tonnes of $\mathrm{CO}_{2}$ per year, including 74 million tonnes form Europe. To these figures should be added gas emissions from the process of extracting oil resources (global plastic production absorbs $6.0 \%$ of the world's demand for oil) (Ellen MacArthur Foundation, 2017).

Another cause for concern are the chemical additives, which are the main (besides polymers) component of plastics. It has been proven that these stabilisers, plasticisers or pigments (for example bisphenol A and certain phthalates) have a negative impact on human health and the environment. A review of studies analysing occurrence of plastic additives in the marine environment, as well as their effects on and transfers to marine organisms was carried out by Ludovic et al. (2017). They show that as a consequence of plastic accumulation and fragmentation in oceans, plastic additives could represent an increasing ecotoxicological risk for marine organisms. Furthermore, there are also uncertainties about the potential consequences of their long-term exposure to other substances, their combined effects and the consequences of leakage into the biosphere.

In response to environmental problems, scientists begun to undermine growth concepts based on continuous growth in production, consumption and the unlimited exploitation of resources (Meadows et al., 1972; Millennium Ecosystem Assessment, 2005; Rockström et al., 2009). It was argued that the growth must be sustainable and not disturb ecosystems. The concept of sustainable development took a prominent place in the discourse on the natural environment and is now the foundation of key socio-economic, political and environmental activities (Adams, 2009). Unfortunately, the effects of implementing this concept are not satisfactory.

One of the great contemporary challenges are limits of the linear model, in which an increase in production entails an increase in resources obtained from the environment and leaves behind waste with disregard of the sustainability of the process. Undoubtedly, this system was highly successful in generating material wealth but in recent decades it has demonstrated weaknesses due to resources depletion and destructive impact on the environment. Projections of further effects of the linear economy (in the face of the growing population, in particular middle class, being future consumers), leave no illusions - world's natural tolerance to human activity appears to be exhausted (Steffen et al., 2015). On top of this, there is also a solid economic argument - reuse of waste can significantly reduce costs (Hestin et al., 2015). 
Scientists argue that the linear model must be replaced by a new one, circular, that would provide the necessary goods and services for maintaining and improving living standards of growing population without ever increasing the consumption of raw materials and the quantity of waste. While the concept of circular economy (CE) emerged as a political aim in the last decade, its origins have a longer story which goes back to concerns regarding the limits of growth and resource scarcity raised by Boulding (1966). The following years brought further conceptual development of the idea of circularity. Nowadays, this idea has attracted an expanding body of research and literature from different fields and geographical areas (Bocken et al., 2017; Ghisellini et al., 2016; Lieder \& Rashid, 2016). Kirchherr at al. (2017) have gathered 114 CE definitions which were coded on 17 dimensions. Their findings indicate that the circular economy is most frequently depicted as a combination of reduce, reuse and recycle activities. One of the most popular definitions (Ellen MacArthur Foundation, 2013) assumes that the circular economy is a system that is restorative and regenerative by design. It is based on three basic principles: preserving and enhancing natural capital (through the regulated usage of available resources, and the balance of renewable resource flow), optimising resource yields (which means that remanufacturing, refurbishing and maintenance are well-planned, in order to make materials a part of economic processes for as long as possible) and fostering system effectiveness (to minimise negative externalities, eliminate toxic substances, by either replacing or reducing them, for example choosing appropriate materials what leads to waste reduction or replacing fossilised energy resources by renewable ones). The transition towards a CE is not limited to certain materials or sectors. It is a systemic change that affects the entire economy and involves all products and services.

\section{Strategy for Plastic in the European Union}

CE has become a strategic goal at the EU level both in the context of environmental restrictions and because of its economic potential. On 2 December 2015, the European Commission (2015) adopted a Circular Economy Package (CEP): Communication and an Action Plan and proposals for revised legislation on waste. An Action Plan (AP) identifies five priority sectors to speed up the transition along their value chain: plastics, food waste, critical raw materials, construction and demolition, biomass and bio-based materials. It consists of out 54 measures to 'close the loop' of product lifecycles, which are intended to help stimulate Europe's transition towards CE and thus boost global competitiveness, foster sustainable economic growth and generate new jobs (in 2019, all these 54 actions proposed in AP have been delivered or are being implemented (European Commission, 2019). As part of the CEP, the EU adopted four directives (amending previous directives): Directive 2018/849 (2018) (on end-of-life vehicles, on batteries and accumulators and waste batteries and accumulators; and on waste electrical and electronic equipment), Directive 2018/850 (2018) 
(on the landfill of waste), Directive 2018/851 (2018) (on waste) and Directive 2018/852 (2018) (on packaging and packaging waste). These acts, especially on waste, imposes several ambitious goals, including:

- targets for waste recovery and recycling (for plastic waste: $55.0 \%$ by 2030 , packaging waste: $70.0 \%^{2}$, municipal waste: $65.0 \%$, and for other types of waste like: wood, ferrous metals, aluminium, glass, paper and cardboard);

- reduction of municipal waste landfilled (to maximum of $10.0 \%$ by 2035);

- imposes the need to create incentives for the use of recycled packaging materials in the manufacturing (including targets for recycled packaging waste);

- requires packaging to comply with ,essential requirements' (minimisation of packaging volume and weight, and the design of packaging to permit its reuse/recovery).

Other recycling targets defined in CEP do not focus directly on plastic waste but refer to a certain waste stream that can contain mixed materials, include plastics (recycling targets among others for WEEE - waste electrical and electronic equipment, ELV - end of life vehicles, building \& construction). Generally, the regulations are primarily aimed at preventing waste and, when this is not possible, supporting its recycling and recovery. Landfilling should be systematically reduced, and treatment and reuse should become an increasingly common solution.

An essential part of the CEP is a Strategy for Plastic (European Commission, 2018a), which is the first EU-wide policy framework based on a material-specific lifecycle-approach to integrate circular design, use, reuse and recycling activities into plastics value chains. The strategy aims to reduce the amount of plastic waste by creating the conditions under which the production of plastic products will be adapted to reuse needs and recycling will be a cost-effective solution for businesses. The most significant piece of legislation is Directive 2019/904 (2019) on the reduction of the impact of certain plastic products on the environment (so called The Single-Use Plastics Directive, SUP). The regulations came from concerns about the size of water pollution (80.0 to $85.0 \%$ all waste found on European beaches is made of plastic; about a quarter of these are abandoned or lost fishing gear and $43.0 \%$ are single-use plastic items, which are usually used outside - in the streets or fast gastronomy). SUP complements the measures already envisaged under the EU Plastics Strategy, addressing the identified gaps in the existing actions and legislation, and further reinforcing the EU's systemic approach to this issue. The Plastics Strategy already includes specific measures on microplastics (restrictions for deliberately added microplastics in products and oxo-plastics as well as measures for microplastics from other sources: tyres, textiles and plastic pellets), and the SUP focusses on single use plastics and fishing gear containing plastic, which are macro-plastics. SUP applies to the 10 most found single use items and fishing gear (they represent around $70.0 \%$ of marine litter items by count) — from July 2021 they will be

2 Packaging waste is broken down into plastic packaging waste and wooden packaging waste. 
banned. Some of the single use items will be restricted, which is supposed to reduce their use. Some will need to contain information on how to get rid of them in a way that is as friendly to nature as possible. Manufacturers of other items will bear the costs of their disposal and cleaning, and will be forced to carry out information campaigns about the adverse impact of their products. Member states will have to achieve a $90.0 \%$ collection target for plastic bottles by 2029 , and plastic bottles will have to contain at least $25.0 \%$ of recycled content by 2025 and $30.0 \%$ by 2030 . All the restrictions and orders are intended to achieve the main goal: by 2030 all plastic packaging on the EU market should be reusable or recyclable and the consumption of single-use plastics must decrease significantly.

In 2018, European Commission (2018b) developed a monitoring framework to track progress towards the CE. To assess the EU countries' efforts in reducing plastic waste, two main indicators will be evaluated: (1) recovery and landfill rate of plastic waste and (2) recycling rate of plastic packaging (as a type of recycling rate of packaging waste). However, the progress in plastic waste reduction will be reflected also in other $\mathrm{CE}$ indicators (total waste generation, rate of municipal waste, recycling rate of municipal waste).

Member states must transpose the provisions of the directives into their legislation. Responsibility of stakeholders (including producers of specific products and packaging) will no longer be only good will, but an obligation imposed by law. However, there are already companies that have set their own circularity goals (or even are pioneers in this area, e.g. in Renalut, Philips, Unilever, M\&S). This will certainly improve their competitive position (other entities will have to keep up with legal regulations and the growing demands of customers). It should be noted that there is a solid public support (about $90.0 \%$ of respondents) for EU measures aimed at reducing plastic waste (European Commission, 2017). However, people still don't make a greater effort to increase circularity on their own (only about $60.0 \%$ of respondents have separated most of their waste for recycling in last six months and $35.0 \%$ avoided single-use plastic goods other than plastic bags). Despite the growing ecological awareness, actions aimed at its further increase are necessary. Due to the scale of the changes, financial incentives for enterprises are crucial as well (the EU intends to support innovations aimed at making recycling a cost-effective solution for businesses). Another important factor determining expected changes is the role of the state and the way it will regulate the market. Directives require certain results, but the choice of tools and instruments is up to the member states.

\section{Results}

The goals set in CEP are ambitious but realistic to meet in the coming years. At this time, the EU countries' efforts in reducing plastic waste can be assessed only as a result of their own aims and motives. Countries implement their circular strategies not only for environmental but also for economic reasons. The 
transition entails new investment which remains an important factor in the face of declining growth rates and will contribute to cost reduction (Ellen MacArthur Foundation et al., 2015; Vuta et al., 2018). Finland, Italy and the Netherlands have integrative roadmaps in order to achieve a full CE model before a certain year; Germany's Closed Substance Cycle and Waste Management Act promotes multi-use, low-waste, long-life and repair-friendly products; Sweden, Portugal (and also Germany) aim their programs at a specific industry - green and bioeconomic sectors, while Spain, Slovakia, France, Belgium and Romania integrate $\mathrm{CE}$ aspects to their national strategies through waste management which is considered as an essential part of CE. The United Kingdom is also advanced on the way to economic transformation, however different approaches have emerged (e.g. in England and Northern Ireland there is no formal strategy and the circularity is supported by extensive and voluntary measures, while in Scotland and Wales comprehensive strategies have been adopted).

The efficiency of plastic waste management in the EU is improving: between 2006 and 2016, the amount of plastic waste collected for recycling increased by $79.0 \%$, for energy recovery by $61.0 \%$ and the amount of landfilled waste decreased by $43.0 \%$ (chart 1 ). However, the problem is that energy recovery rate $(41.6 \%)$ is still higher than the recycling rate $(31.1 \%)$, and the recycling rate only slightly exceeds the landfill rate $(27.3 \%)^{3}$. In 9 countries plastic waste is mainly landfilled. The highest landfill rate of plastic waste was observed in: Malta (82.0\%), Greece (78.0\%), Cyprus and Bulgaria (75.0\%), while the lowest in: Austria, Germany, the Netherlands and Sweden (less than 2.0\%) (PlasticsEurope, 2018).

There is also a progress in the field of recycling rate of packaging plastic waste. This indicator increased form $24.0 \%$ in 2005 to $42.4 \%$ in 2016 (chart 2).

3 The most advantageous way to manage plastic waste, both economically and environmentally, is recycling. It is a method preventing accumulation the excessive waste quantity through their second processing and utilization in the production process of new materials. The simplest and most commonly used is mechanical recycling, by which waste materials are recycled into 'new' (secondary) raw materials without changing its basic structure (it's a physical process in which plastic waste are formed by cutting, shredding or washing into granulates, flakes or pellets of appropriate quality for manufacturing, and then melted to make the new product by extrusion). More difficult, but at the same time more effective, is chemical recycling. It involves the transformation of plastics, i.e. plastic polymers, by means of heat and/or chemical agents to yield monomers or other hydrocarbon products that may be used to produce new polymers, refined chemicals or fuels (Ragaert et al., 2017). Reusing plastics has many advantages, characterised by (1) conservation of fossil fuels since plastic production uses $4.0-8,0 \%$ of global oil production, i.e. $4.0 \%$ as feedstock and $4.0 \%$ during conversion (2) reduction of energy and municipal solid waste, and (3) reduction of carbon-dioxide $\left(\mathrm{CO}_{2}\right)$, nitrogen-oxides and sulphur-dioxide emissions (Al-Salem et al., 2009). The worst (both from the environmental and economical point of view), but at the same time the most common way of plastic waste disposing in the EU is energy recovery. It is the combustion of plastic waste to produce energy in the form of heat, steam and electricity (Wasilewski \& Siudyga, 2013; Wollny et al, 2008). 
The highest increase of this rate was observed in Cyprus (from 8.7\% to 63.0\%), Lithuania (from 21.2\% to $74.0 \%$ ) and Bulgaria (from 8.4\% to 52.6\%). In 2015, the lowest recycling rate of packaging plastic waste was observed in Estonia (24.6\%), Finland (25.4\%) and France (25.8\%). In Poland the rate increased from $24.6 \%$ to $46.9 \%$. Generally, the new EU countries recorded the largest changes over the period 2006-2016 than EU-15. As a result, the average level of recycling rate of plastic packaging waste is higher (47.6\%) than in the EU-15 (38.3\%) The new EU countries also generate less municipal and plastic waste. The countries with the lowest rates are: Croatia (13.2 kg/person), Bulgaria (15.1) and Romania (18) while the highest: Ireland (58 kg/person), Luxembourg (53), Estonia (49) and Germany (37.6) (Eurostat, 2018).

Single-use plastic packaging accounts for about $60.0 \%$ of the plastic waste in the EU. $64.0 \%$ of the post-consumer plastic packaging waste is generated from households while $36.0 \%$ from the trade and industry segment. It is estimated that the economic losses resulting only from the single-use plastic packaging amount to $95.0 \%$ of their material value, which is between EUR 70 and 105 billion per year (European Association of Plastics Recycling and Recovery Organizations, 2019; Eurostat 2018). Despite plastic waste management improves, the plastic reuse and recycling rates are still very low, particularly in comparison with other materials such as paper, glass or metals. What's more, a large part of plastic waste is shipped outside the EU (mainly to China, which is the world's largest importer of waste), where is further processed (Eurostat, 2018). This situation is mainly due to the under-developed recycling sector and very low demand for recycled plastics which represents only about 6.0\% of the demand for plastics (European Association of Plastics Recycling and Recovery Organizations, 2019). Many countries still do not have an effective separate collection system in place. The level of public awareness is also quite low. Potential for recycling of plastics waste remains therefore largely unexploited.

\section{Conclusion}

Firstly, in the last years, the EU countries have improved their efficiency in the management of plastic waste but still a large share of plastic is wasted (74.0\%) - either sent to landfill or used for energy recovery. Generally, the new EU countries recorded the largest changes in recycling rate over the period 2006-2016 than EU-15. In 2016 this indicator is higher in new EU countries $(47.6 \%)$ than in the EU-15 (38.3\%).

Secondly, the scale of the problem associated with improper management of plastic waste entails economic costs and, above all, irreversible losses for the environment. Adopting first ever European plastics strategy, EU addresses environmental problems and solutions to help the transition to CE. The slogans with which this model is connected could be compared to the concept of sustainable development or corporate social responsibility. However, while these concepts were mainly reduced to image activities, it seems that the idea of $\mathrm{CE}$ 
is becoming a reality. Certainly, achieving full circularity in the EU will require a lot of time, but legal regulations will enforce specific behaviors among stakeholders. The directives will have to be transposed into the legislation of the member states. Stakeholders responsibility will no longer be only good will, but an obligation imposed by law. Add to this the growing consumer awareness, then real changes can be expected.

Thirdly, there are a lot of challenges to achieve EU targets in the area of plastic management. Setting high targets is necessary to spur higher recycling performance but a prerequisite to meet them is a removal of barriers. It is necessary to increase the European capacity in sorting and recycling facilities for accommodating increased quantities of plastic waste. Expanding current capacity will require extra costs but also there is the potential of creating economies of scale that will enable higher recycling efficiency at lower costs. This potential is created by the size of the European plastics industry and its dynamic growth. However, a basic condition is to boost the demand of recycled plastics in the market (currently, the demand for recycled plastics represents only about 6.0\% of the demand for plastics). It is necessary to create stable market conditions for recycled plastics and enable recyclers to invest in capacities and new technology. In addition, an effective regulatory frameworks are needed - accountability and transparency in the way data are collected at the output of the recycling process and how the recycling rates and the targets are calculated.

Fourthly, promotion of sustainable and green consumption patterns which can themselves provide the basis for social innovation and social entrepreneurship are a very important factor. Changes in consciousness are already taking place, but due to the current state of the environment, there is a need to accelerate this process.

\section{References}

Adams, W.M. (2009). Green development: environment and sustainability in a developing world. London: Routledge.

Al-Salem, S.M., Lettieri, P., \& Baeyens, J. (2009). Recycling and recovery routes of plastic solid waste (PSW): a review. Waste Management, 29(10). doi:10.1016/j.wasman.2009.06.004.

Ambrogi, V., Carfagna, C., Cerruti, P., \& Marturano, V. (2017). Additives in polymers. In C.F. Jasso-Gastinel, \& J.M. Kenny (Eds.), Modification of polymer properties. Boston: Elsevier. doi:10.1016/B978-0-323-44353-1.00004-X.

Bocken, N.M.P., Olivetti, E.A., Cullen, J.M., Potting, J., \& Lifset, R. (2017). Taking the circularity to the next level: a special issue on the circular economy. Journal of Industrial Ecology, 21(3). doi:10.1111/jiec.12606.

Boulding, K. (1966). The economics of the coming spaceship earth. In: H. Jarrett, (Ed.), Environmental quality in a growing economy. Baltimore: Johns Hopkins University Press. 
Directive (EU) 2018/849 of the European Parliament and of the Council of 30 May 2018 amending Directives 2000/53/EC on end-of-life vehicles, 2006/66/EC on batteries and accumulators and waste batteries and accumulators, and 2012/19/EU on waste electrical and electronic equipment (OJ L 150).

Directive (EU) 2018/850 of the European Parliament and of the Council of 30 May 2018 amending Directive 1999/31/EC on the landfill of waste (OJ L 150).

Directive (EU) 2018/851 of the European Parliament and of the Council of 30 May 2018 amending Directive 2008/98/EC on waste (OJ L 150).

Directive (EU) 2018/852 of the European Parliament and of the Council of 30 May 2018 amending Directive 94/62/EC on packaging and packaging waste (OJ L 150).

Directive (EU) 2019/904 of the European Parliament and of the Council of 5 June 2019 on the reduction of the impact of certain plastic products on the environment (OJ L 155).

Ellen MacArthur Foundation, Stiftungsfonds für Umweltökonomie und Nachhaltigkeit, \& McKinsey Center for Business and Environment. (2015). Growth within: a circular economy vision for a competitive Europe. Retrieved 16.12.2018 from https: / www.ellenmacarthurfoundation.org.

Ellen MacArthur Foundation. (2013). Towards the circular economy. Retrieved 15.12.2018 from https://www.ellenmacarthurfoundation.org.

Ellen MacArthur Foundation. (2017). The new plastics economy: rethinking the future of plastics \& catalysing action. Retrieved 20.12.2018 from https://www. ellenmacarthurfoundation.org.

European Association of Plastics Recycling and Recovery Organizations. (2019). Retrieved 18.12.2018 from http://www.epro-plasticsrecycling.org.

European Commission. (2015). Communication from the Commission to the European Parliament, the Council, the European Economic and Social Committee and the Committee of the Regions: closing the loop: an EU action plan for the circular economy (COM/2015/0614).

European Commission. (2017). Special Eurobarometer 468: attitudes of European citizens towards the environment. Retrieved 20.11.2018 from https://ec.europa.eu.

European Commission. (2018a). Communication from the Commission to the European Parliament, the Council, the European Economic and Social Committee and the Committee of the Regions: a European strategy for plastics in a circular economy (COM/2018/028).

European Commission. (2018b). Communication from the Commission to the European Parliament, the Council, the European Economic and Social Committee and the Committee of the Regions: on a monitoring framework for the circular economy $(\mathrm{COM} / 2018 / 029)$. 
European Commission. (2019). Report from the Commission to the European Parliament, the Council, the European Economic and Social Committee and the Committee of the Regions: on the implementation of the circular economy action plan (COM/2019/190).

Eurostat. (2019). Retrieved 20.12.2018 from https://ec.europa.eu.

Geyer, R., Jambeck, J.R., \& Law, K.L. (2017). Production, use, and fate of all plastics ever made. Science Advances, 3(7). doi:10.1126/sciadv.1700782.

Ghisellini, P., Cialani, C., \& Ulgiati, S. (2016). A review on circular economy: the expected transition to a balanced interplay of environmental and economic systems. Journal of Cleaner Production, 114. doi:10.1016/j. jclepro.2015.09.007.

Hestin, M., Faninge, T., \& Milios, L. (2015). Increased EU plastics recycling targets: environmental, economic and social impact assessment. Retrieved 17.12.2018 from https://www.plasticsrecyclers.eu.

Jambeck, J., Geyer, R., Wilcox, C., Siegler, T.R., Perryman, M., Andrady, A., Narayan, R., \& Law, K.L. (2015). Plastic waste inputs from land into the ocean. Science, 437(6223). doi:10.1126/science.1260352.

Kirchherr, J., Reike, D., \& Hekkert, M. (2017). Conceptualizing the circular economy: an analysis of 114 definitions. Resources, Conservation \& Recycling, 127. doi:10.1016/j.resconrec.2017.09.005.

Lieder, M., \& Rashid, A. (2016). Towards circular economy implementation: a comprehensive review in context of manufacturing industry. Journal of Cleaner Production, 115. doi:10.1016/j.jclepro.2015.12.042.

Ludovic, H., Alexandre, D., Ika, P., Camille, L., Ronan, J., Philippe, S., \& Guillaume, D. (2017). Occurrence and effects of plastic additives on marine environments and organisms: a review. Chemosphere, 182. doi:10.1016/j. chemosphere.2017.05.096.

Meadows, D.H., Meadows, D.L., Randers, J., \& Behrens III, W.W. (1972). The limits to growth. New York: Universe Books.

Millennium Ecosystem Assessment. (2005). Ecosystems and human well-being: general synthesis. Retrieved 17.12.2018 from http://www.millenniumassessment.org.

National Ocean Service. (2019). Retrieved 15.12.2018 from https://oceanservice.noaa.gov.

PlasticsEurope. (2018). Plastics: the Facts 2018: an analysis of European plastics production, demand and waste data. Retrieved 15.12.2018 from https://www. plasticseurope.org.

Ragaert, K., Delva, L., \& Van Geem, K. (2017). Mechanical and chemical recycling of solid plastic waste. Waste Management, 69. doi:10.1016/j. wasman.2017.07.044.

Rockström, J., Steffen, W., Noone, K., Persson, A., Chapin III, F.S., Lambin, E.F., ... Foley, J.A. (2009). A safe operating space for humanity. Nature, 461(7263). doi:10.1038/461472a. 
Science History Institute. (2018). History and future of plastics. Retrieved 20.11.2018 from https://www.sciencehistory.org.

Steffen, W., Richardson, K., Rockstrom, J., Cornell, S.E., Fetzer, I., Bennett, E.M., ... Sorlin, S. (2015). Planetary boundaries: guiding human development on a changing planet. Science, 347(6223). doi:10.1126/science.1259855.

Vuta, M., Vuta, M., Enciu, A., \& Cioaca, S.I. (2018). Assessment of the circular economy's impact in the EU economic growth. Amfiteatru Economic, 20(48). doi:10.24818/EA/2018/48/248.

Wasilewski, R., \& Siudyga, T. (2013). Energy recovery from waste plastics. Chemik, 67(5).

Watkins, E., \& Brink, P. (2017). Marine litter: socio-economic study. Retrieved 20.11.2018 from https://wedocs.unep.org.

Wollny, V., Dehoust, G., Fritsche, U.R., \& Weinem, P. (2008). Comparison of plastic packaging waste management options: feedstock re-cycling versus energy recovery in Germany. Journal of Industrial Ecology, 5(3). doi:10.1162/108819801760049468.

\section{Acknowledgements}

Author contributions: author has given an approval to the final version of the article.

Funding: this research was funded by the Wroclaw University of Economics and Business statutory sources.

Note: the results of this study were presented at 10th International Conference on Applied Economics Contemporary Issues in Economy (June 27-28, 2019, Torun, Poland). 


\section{Appendix}

Chart 1.

Recovery and landfill rate of plastic waste in European countries in 2016 (in \%)

100

80

60

40

20

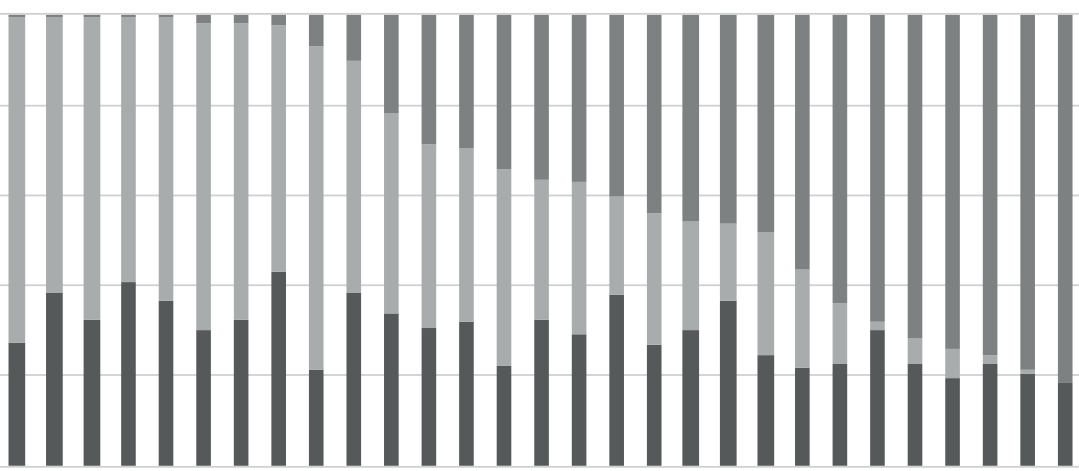

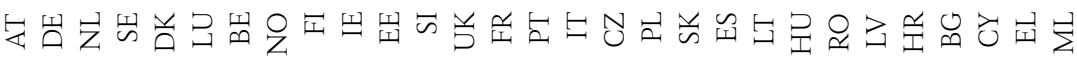

recycling rate

nenergy recovery rate

landfill rate

Source: Own preparation based on PlasticsEurope (2018).

Chart 2.

Recycling rate of packaging plastic waste in UE in 2005 and 2016 (in\%)

80

60

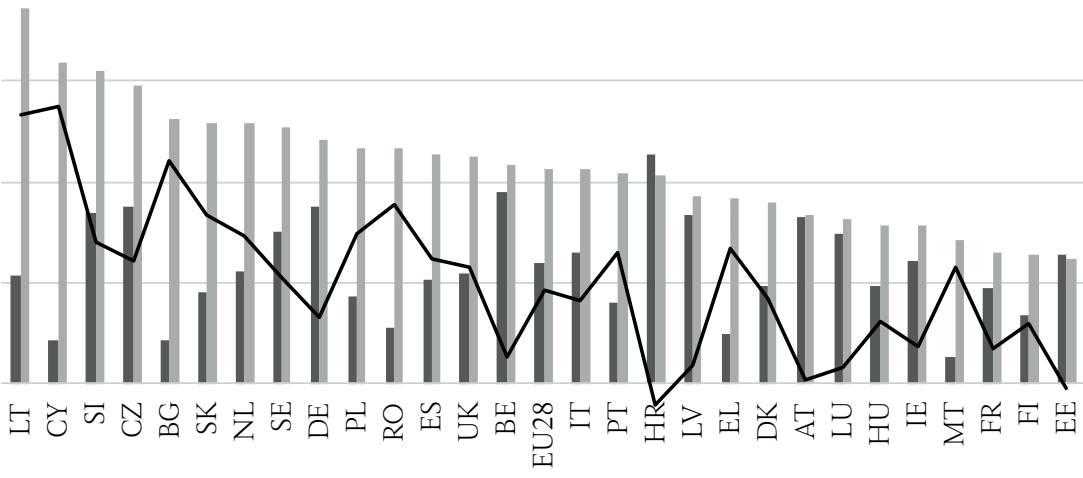

$-20$

2005

2016

change

Note:

In Croatia, the data refer to years: 2012 and 2016.

Source: Own preparation based on Eurostat (2018). 